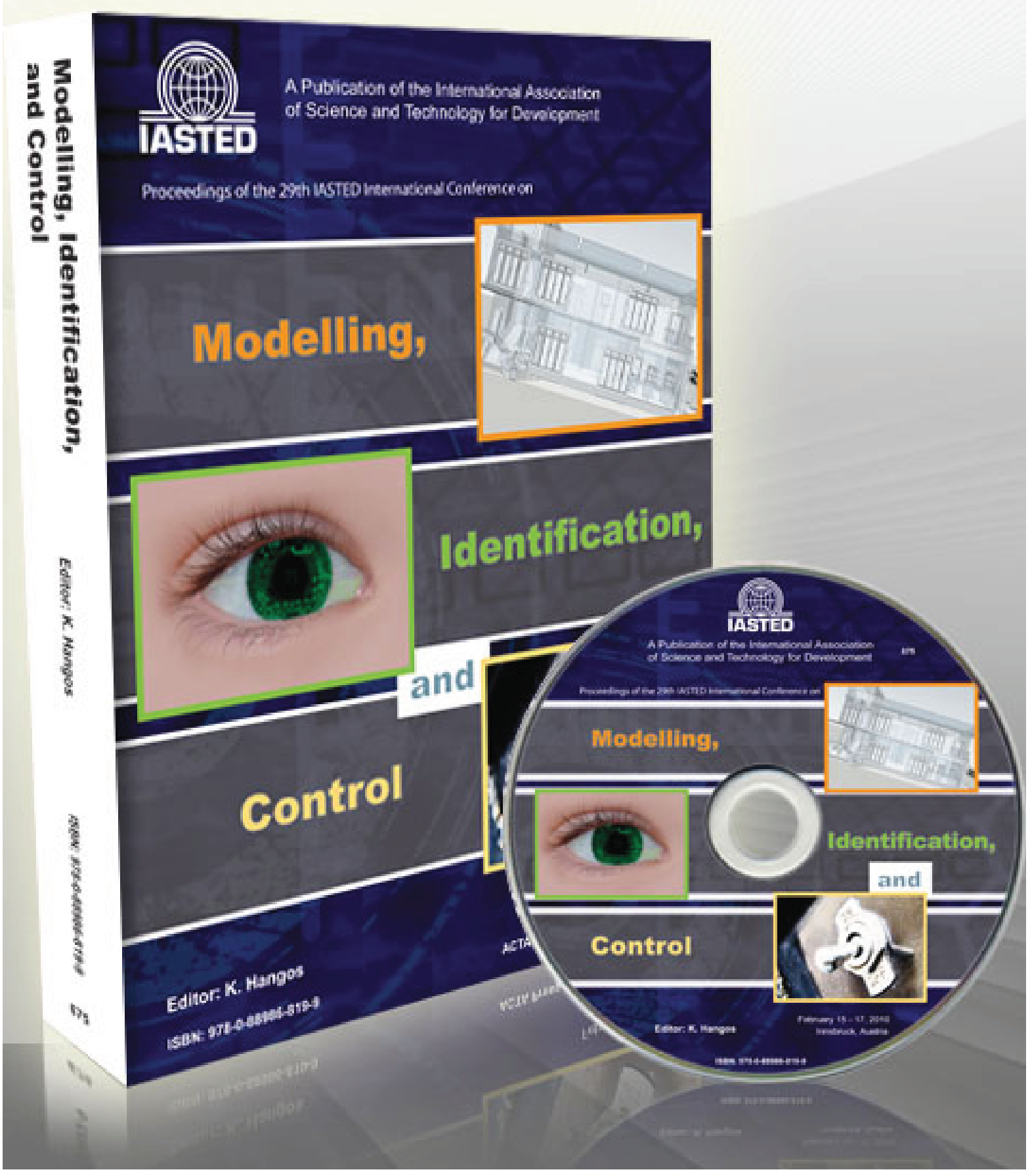




\title{
ELECTRIC VEHICLE DRIVE SYSTEM WITH ADAPTIVE PID CONTROL
}

\author{
Micael S. Couceiro ${ }^{1}$, Carlos M. Figueiredo ${ }^{2}$, C. Lebres $^{3}$ N. M. Fonseca Ferreira ${ }^{3}$, J. A. Tenreiro Machado ${ }^{4}$ \\ ${ }^{(1,2,3)}$ Institute of Engineering of Coimbra, Portugal \\ (e-mail: micaelcouceiro@gmail.com,ccfigueiredo@gmail.com, clebres@isec.pt nunomig@isec.pt) \\ ${ }^{(4)}$ Institute of Engineering of Porto, Portugal \\ (e-mail: jtm@isep.ipp.pt)
}

\begin{abstract}
The aim of this work is to implement an adaptive $P I D$ $S I S O$ feedback control to obtain a fine adjustment of an electric vehicle $(E V)$ driving system. Our research work is done under different operating conditions, namely, variable battery voltage and variable load. A comparison between conventional and adaptive PID algorithms is established when they are applied to the above mentioned conditions. Experimental results indicate that the adaptive PID controller leads to a faster response and a better stability. Furthermore, the adaptive PID controller follows a given reference velocity faster and more smoothly than the conventional PID controller.
\end{abstract}

\section{KEY WORDS}

PID control, Electric vehicle, Drive system

\section{Introduction}

The development of $E V \mathrm{~s}$ is motivated by global concerns over the need for environmental protection. McGrawHill's AccessScience Encyclopedia defines an $E V$ as "a ground vehicle propelled by a motor that is powered by electrical energy from rechargeable batteries" [1].

In fact, $E V \mathrm{~s}$ are playing an important role in solving problems caused by internal combustion engine vehicles (ICEVS) and are becoming more and more necessary all over the world. In recent years several researchers have investigated the use of PID, fuzzy logic, and adaptive control techniques for the driving control of $E V s[2,3]$. The drive system of $E V S$ will suffer disturbances inevitably during its operating process. Therefore, in order to achieve an ideal dynamic behaviour, we must have good control techniques.

Though the use of PID control has been a long history in the field of control engineering, the three controller parameters are usually fixed. The disadvantage of the PID controller is its poor capability when dealing with system uncertainty, namely parameter variations and external disturbances.

Based on experimental data we show that classical linear control such as the PID algorithm cannot handle the nonlinearities present in the system, resulting in a poor response.

This paper proposes an adaptive PID in order to stabilize the system and to minimize the error between the real velocity and the reference, in spite of the large perturbations in load rotational inertia in all kinds of driving cycles.

The paper is organized as follows. Section two presents the state of the art. Section three, provides an overview of the $E V$ drive system. Section four analyses the traditional control, while section five studies the adaptive control. Finally, section six outlines the main conclusions.

\section{State of the Art}

With the development of navigation technologies for autonomous vehicles and the increase of the processing computers capacity, industrial mobile robot appeared as an important research area [4]. The $A G V$ (Automatic Guided Vehicle) and $A S / R S$ (Automatic Storage/Retrieval System) are devices with wider application in industry (Figure 1).

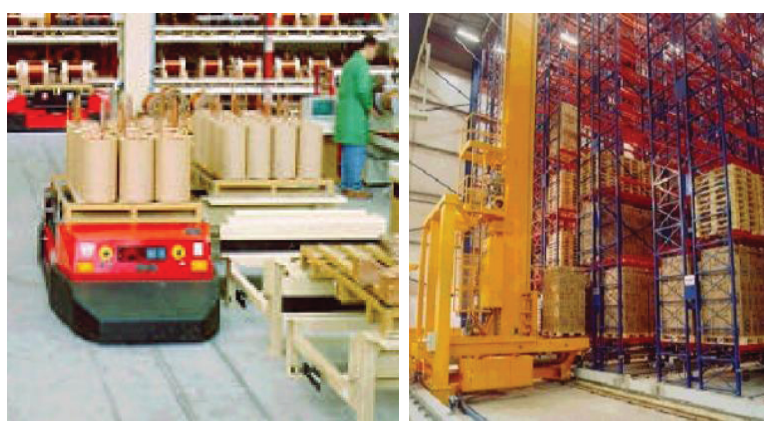

Figure 1. $A G V$ and $A S / R S$ in the industry

Rocha (Rocha et al. 2001) makes a description of mobile robots designed and installed in Portugal. The analysis is focused in $A G V$ and $A S / R S$ projects, making a classification of these systems and pointing-out the most relevant design, implementation and control aspects.

Butdee [5] presents an Automate Guided Vehicle ( $A G V$ ) 
involving an algorithm based on memorized path and the kinematics determination of the movement is developed. It is a three wheels vehicle. The front wheel is used for driving and steering with DC motors and the two rear wheels are free with encoders in order to measure the vehicle displacement, making possible to calculate its real time position and orientation. The choice of the positioning of the encoders on the free wheels provides to the vehicle an accurate measurement of its progression. A programmable logic control $(P L C)$ is used and the control of the $A G V$ motion is implemented through a PID algorithm. Displacement and the steering axis are separated to implement the motion control, while the position and orientation are estimated by a Kalman filter using a state-space model.

Kuo [6] proposes a novel adaptive sliding mode control with PID tuning method for a class of uncertain systems. The goal is to achieve the system robustness against parameter variations and external disturbances. Suitable PID control gain parameters can be computed on-line according to the developed adaptive law. To reduce the high frequency chattering in the switching part of the controller, the boundary layer technique adopted. The proposed method is applied to a brushless DC motor control system. Simulation results demonstrate that satisfactory trajectory tracking is achieved effectively and the input chattering is eliminated.

One hybrid method system that is the most popular presently is neuro-fuzzy systems, which applies a combination of artificial neural networks and fuzzy systems. In fact, authors have proposed the dynamic control using fuzzy logic and neural networks. This type of control is today well established in the area of motion control and particularly in drive systems.

Cao [7] describe a neuro-fuzzy control method for navigation of $A G V$ robot. The significance of Jin Cao work lies in the development of a new method for mobile robot navigation. The system to be controlled is an electrically propelled mobile vehicle, named Bearcat II (Figure 2), consisting in an intelligent control system.

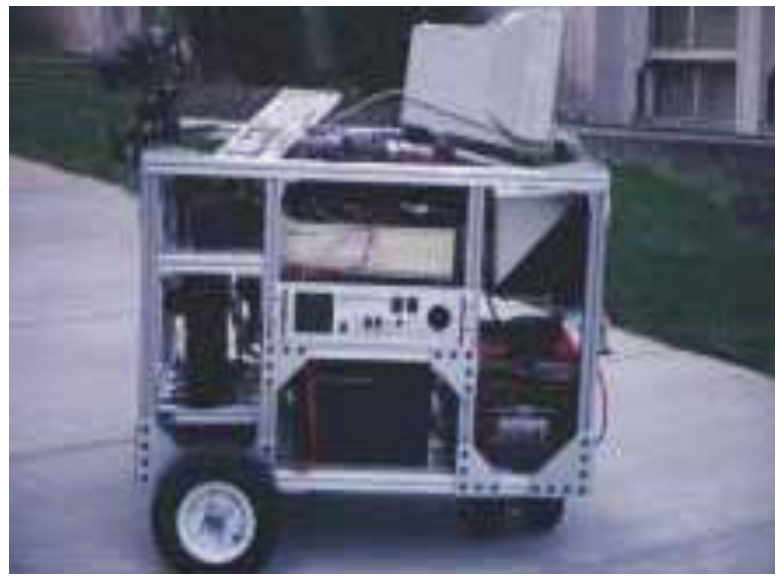

Figure 2. The Bearcat II mobile robot

\section{EV Drive System}

This work is based on experimental data acquired from an $E V$ controlled with a Programmable Logic Controller (PLC) because cost, reliability and safety are a major issue. The objective is to control the $E V$ over the ethernet communicating with the Siemens $P L C$ adopting the PROFINET standard.

The reference velocity is sent to a specific memory word of the $P L C$. The real velocity is calculated based on the encoder pulses of the traction motor (Figure 3).

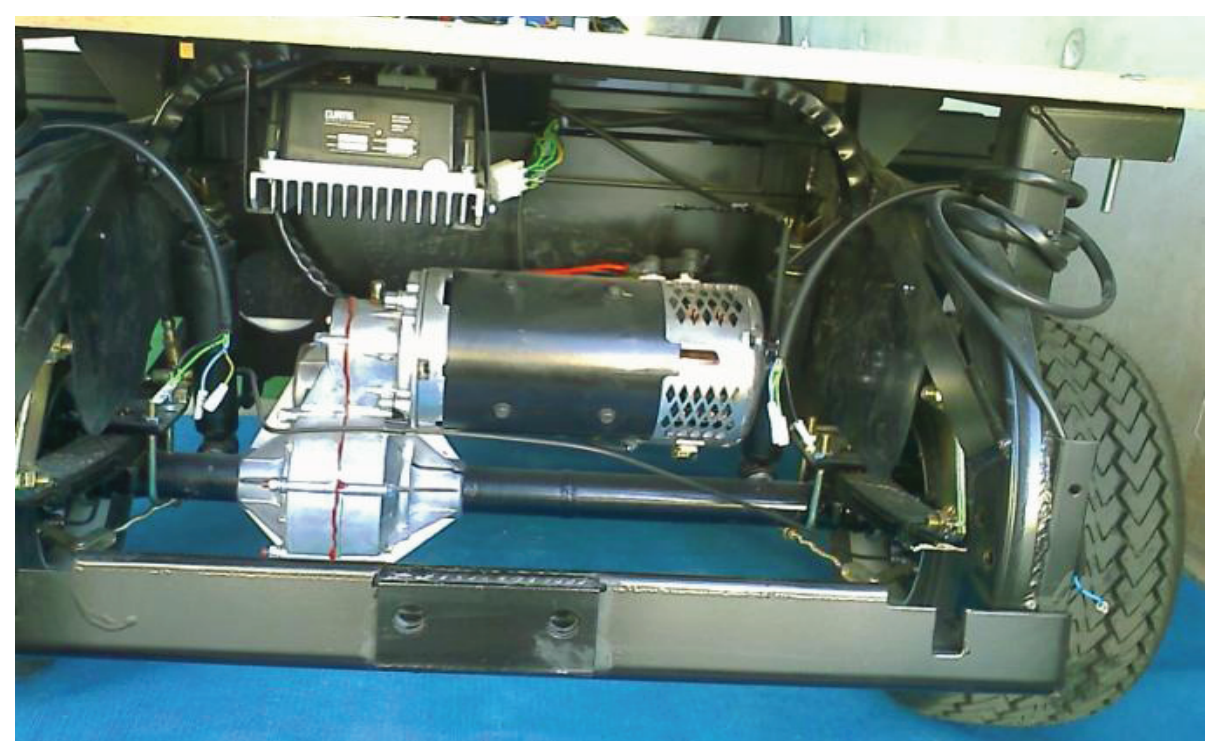

Figure 3. Traction motor 


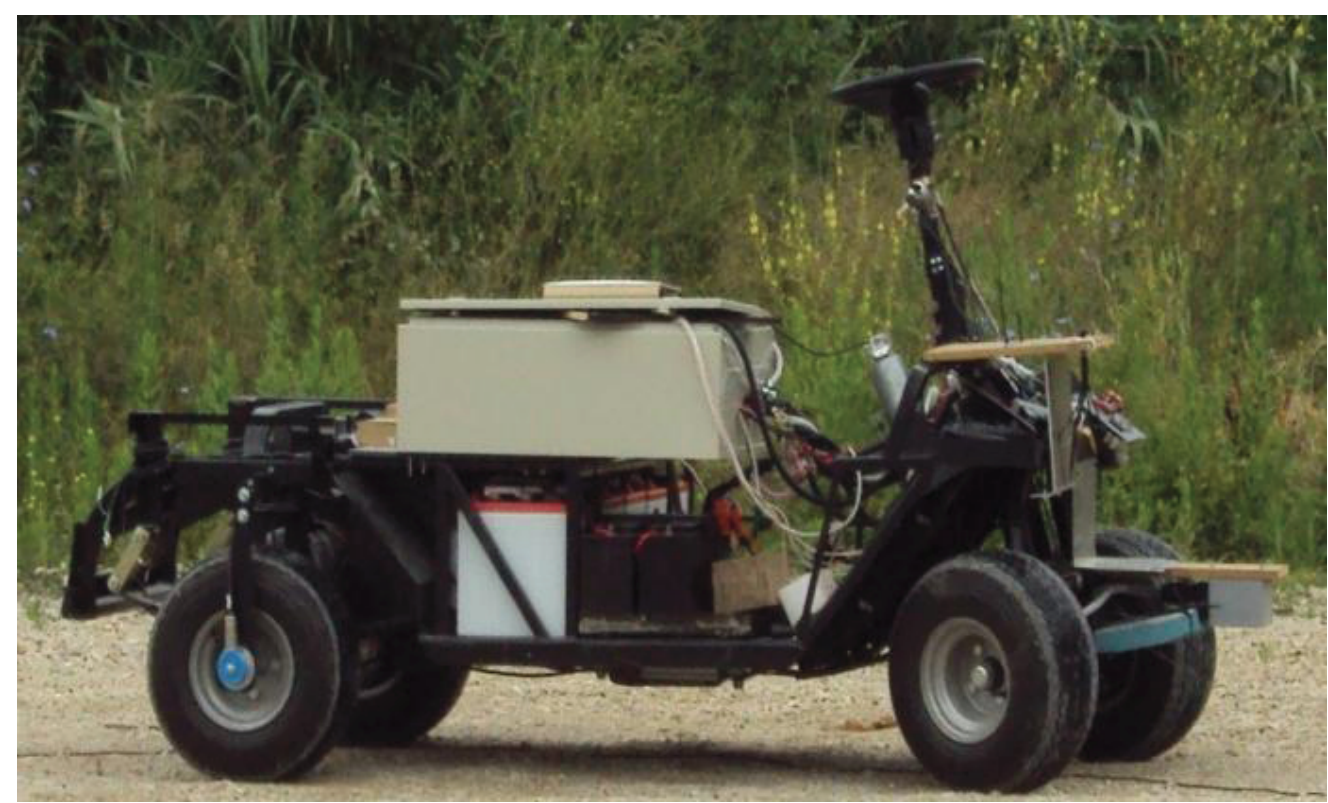

Figure 4. $E V$ based on Melex golf cart

The electric vehicle is based on a Melex golf cart (Figure 4) with the characteristics presented in Table 1.

The Melex 48V Golf Cart is designed as a cost effective and reliable Golf Club Fleet cart with regenerative braking.

Table 1

EV Specifications

\begin{tabular}{|c|c|}
\hline $\begin{array}{c}\text { Dimensions [mm] } \\
\text { Length x Width x Height }\end{array}$ & $2350 \times 1180 \times 1750$ \\
\hline Weigth [Kg] & 550 \\
\hline Battery Voltage [V] & 48 \\
Motor [kW] & 3 \\
Maximum Velocity [km/h] & 25 \\
\hline
\end{tabular}

The difference between the reference velocity and the real velocity will be the error that needs to be minimized. In order to achieve a better response the controller is implemented in the PLC with Ladder. To optimize the time of the tuning process the designer can easily change the controller parameters online over the ethernet.

The traction motor velocity can be controlled with a DC signal logarithmically related with the desired velocity. In order to simplify the control algorithm it is considered a DC signal proportional to the desired velocity, since it is a good approximation for a specific load without any kind of disturbances.

To follow the reference of velocity faster it was decided to sum the controller response with the DC signal that would be necessary to follow the desired velocity leading to a feedforward scheme.

Figure 5 depicts the SISO block diagram of the $E V$ drive system.

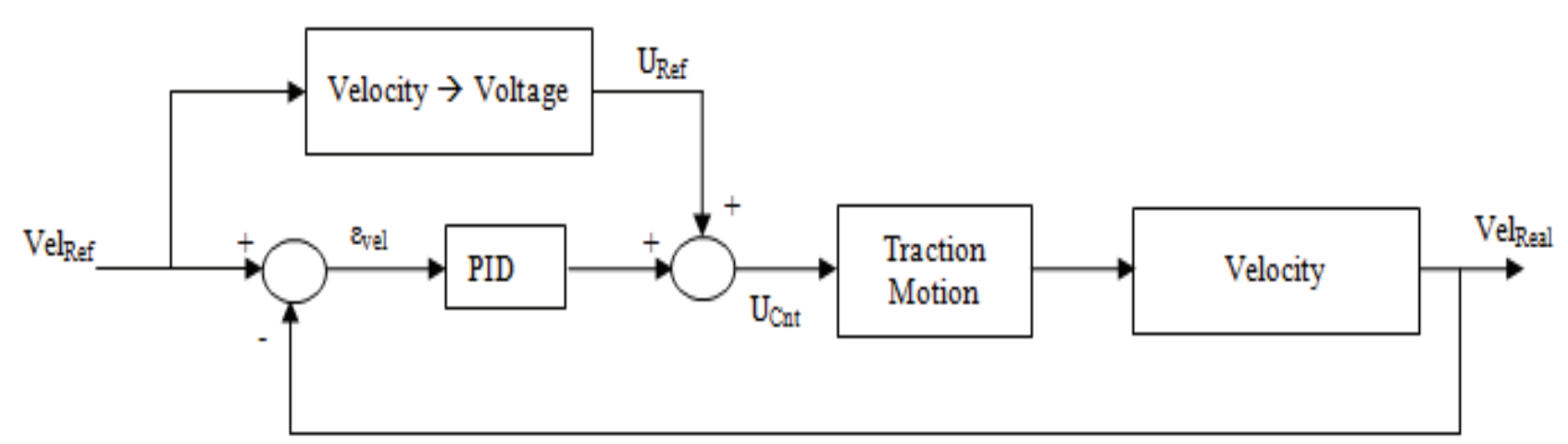

Figure 5. Control diagram 


\section{Classical Control}

The classical PID are the most commonly used control algorithms in industry. Its parameters need to be adjusted according with the control process and remain unchanged during its operation. Among the various existing tuning schemes for PID controllers [8,9], the Ziegler-Nichols (Z$N$ ) method is the most popular and is still extensively used for the determination of the PID parameters.

It is well known that the compensated systems, with controllers tuned by this method, have generally a step response with a high percent overshoot.

The transfer function of the PID controller is:

$$
G_{c}(s)=\frac{U(s)}{E(s)}=K\left(1+\frac{1}{T_{i} s}+T_{d} s\right)
$$

where $E(\mathrm{~s})$ is the error signal and $U(\mathrm{~s})$ is the controller's output. The parameters $K, T_{i}$, and $T_{d}$ are the proportional gain, the integral time constant and the derivative time constant of the controller, respectively.

The design of the PID controller using the second method of $Z-N$ tuning consists on the determination of the optimum PID gains $\left(K, T_{i}, T_{d}\right)$ based on the critical gain $K_{u}$ and the corresponding period of sustained oscillation $T_{u}$ (Table 2).

Table 2

Ziegler-Nichols recipe - Second method
\begin{tabular}{|c|c|c|c|}
\hline Controller Type & $\mathrm{K}$ & $\mathrm{T}_{\mathrm{i}}$ & $\mathrm{T}_{\mathrm{d}}$ \\
\hline$P$ & $0.5 K_{u}$ & $\infty$ & 0 \\
\hline$P I$ & $0.45 K_{u}$ & $T_{u} / 1.2$ & 0 \\
\hline$P I D$ & $0.6 K_{u}$ & $T_{u} / 2$ & $T_{u} / 8$ \\
\hline
\end{tabular}

The critical gain $K_{u}$ and the period of sustained oscillation $T_{u}$ where experimentally acquired using only proportional feedback control $\left(T_{i}=\infty\right.$ and $\left.T_{d}=0\right)$. Increasing the proportional gain $\mathrm{K}$ leads to a state where sustained oscillation occurred at a velocity of $3 \mathrm{Km} / \mathrm{h}$. Under those conditions, the critical gain obtained was $K_{u}=K=400$ and the period of sustained oscillation $T_{u}=3$ seconds.

Following the $Z-N$ second method recipe for the PID controller we obtain the values represented in Table 3.

Table 3

PID controller parameters

\begin{tabular}{|l|l|l|l|}
\hline & $K$ & $T_{i}$ & $T_{d}$ \\
\hline$P I D$ & 240 & 1.5 & 0.375 \\
\hline
\end{tabular}

The values achieved with this method constitute a good first approach for a car operating velocity of $3 \mathrm{Km} / \mathrm{h}$. However the controller does not yields a high performance.

In order to study the system dynamics under the action of the classical PID, during the operation we apply, separately, ramp pulses (ramp-up and ramp-down), at the reference.

The $P L C$ returns the real velocity of the $E V$ every 0.005 seconds.

The charts of Figure 6 depict the experimental results obtained.

Table 4 shows the time response characteristics of the system under the action of the classical PID controller, namely the percent overshoot $P O$, the rise time $t_{r}$, the peak time $t_{p}$ and the settling time $t_{s}$.

\section{Table 4}

Time response parameters of the system under the action of the classical PID controller

\begin{tabular}{|l|l|l|l|l|}
\hline $\boldsymbol{V}_{\text {refmax }}(\mathbf{K m} / \mathbf{h})$ & $\boldsymbol{P O}(\boldsymbol{\%})$ & $\boldsymbol{t}_{\boldsymbol{r}}$ & $\boldsymbol{t}_{\boldsymbol{p}}$ & $\boldsymbol{t}_{\boldsymbol{s}}$ \\
\hline $\boldsymbol{1}$ & 25.83 & 1.01 & 1.80 & - \\
\hline $\mathbf{2}$ & 8.89 & 2.00 & 2.15 & 6.50 \\
\hline $\mathbf{3}$ & 5.78 & 3.05 & 3.50 & 7.00 \\
\hline $\mathbf{4}$ & 5.36 & 4.00 & 4.50 & - \\
\hline $\mathbf{5}$ & 5.98 & 5.07 & 5.91 & - \\
\hline
\end{tabular}

\section{Adaptive Control}

The classical PID would not be enough for the system we are handling because it isn't a linear system. The start up of the PID controller requires a not always simple work in the parameters adjustment, besides the existence of some methodologies [10]. Despite the help of these schemes it is necessary an observation period to survey the controller performance, which requires, in some cases, a substantial amount of time. This may be interpreted as a disadvantage, or a difficulty, in the controller start-up service.

In more complex cases, dynamical phenomena compromise the PID controller performance, making necessary to readjust the controller parameters.

What we will do next is to divide our nonlinear system in multiple linear subsystems based on the reference and real velocity. Like we previously made we will now obtain, for each different condition, a critical gain and a period of sustained oscillation. 

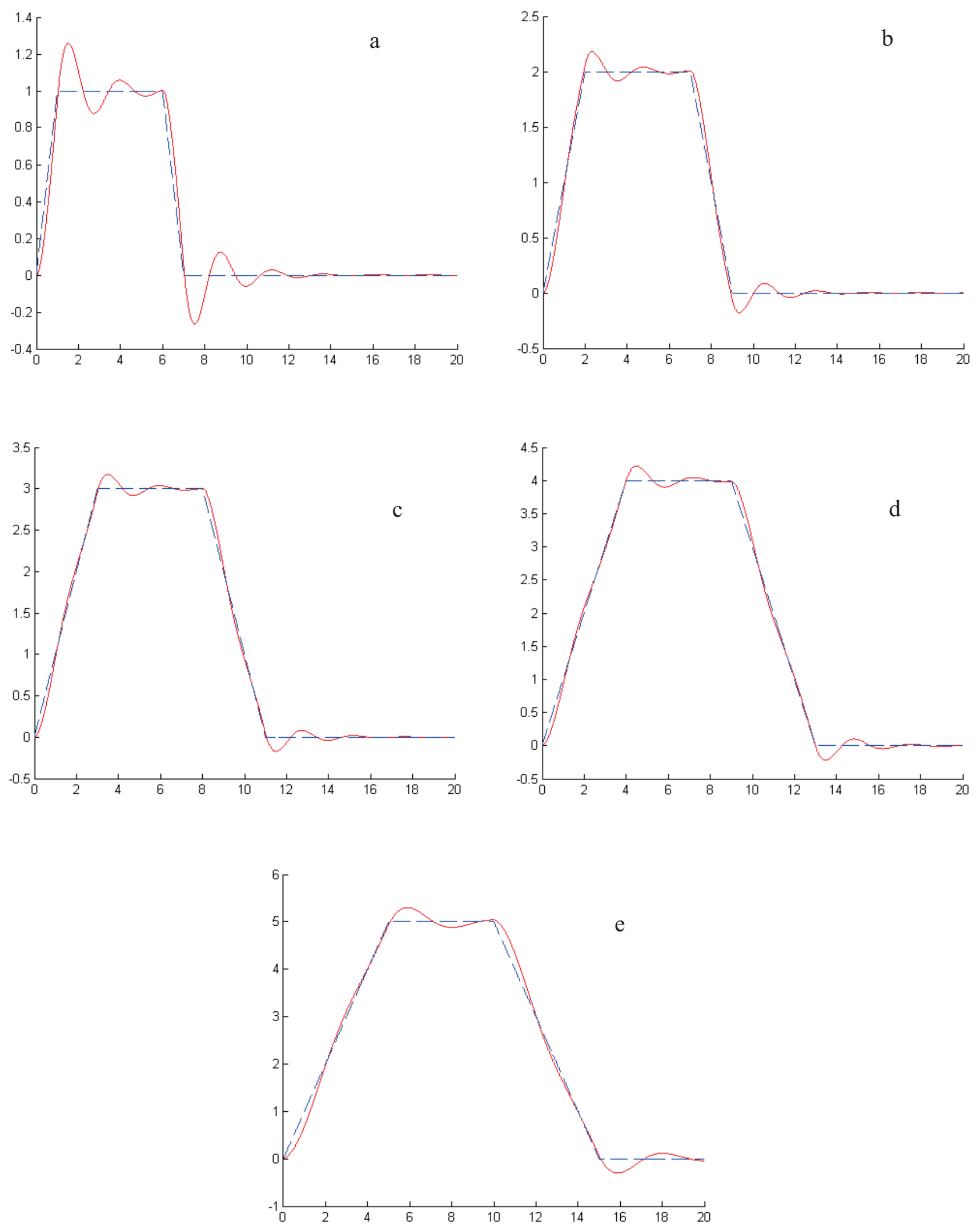

Figure 6. Time response of the $E V$ under the action of the classical $P I D$ controller for ramp with an amplitude of a) $\left.\left.\left.V e l_{R e f}=1 \mathrm{~km} / \mathrm{h} \mathrm{b}\right) V e l_{\text {Ref }}=2 \mathrm{~km} / \mathrm{h} \mathrm{c}\right) V e l_{\text {Ref }}=3 \mathrm{~km} / \mathrm{h} \mathrm{d}\right) V e l_{\text {Ref }}=4 \mathrm{~km} / \mathrm{h} \mathrm{e)} V e l_{\text {Ref }}=5 \mathrm{~km} / \mathrm{h}$ 

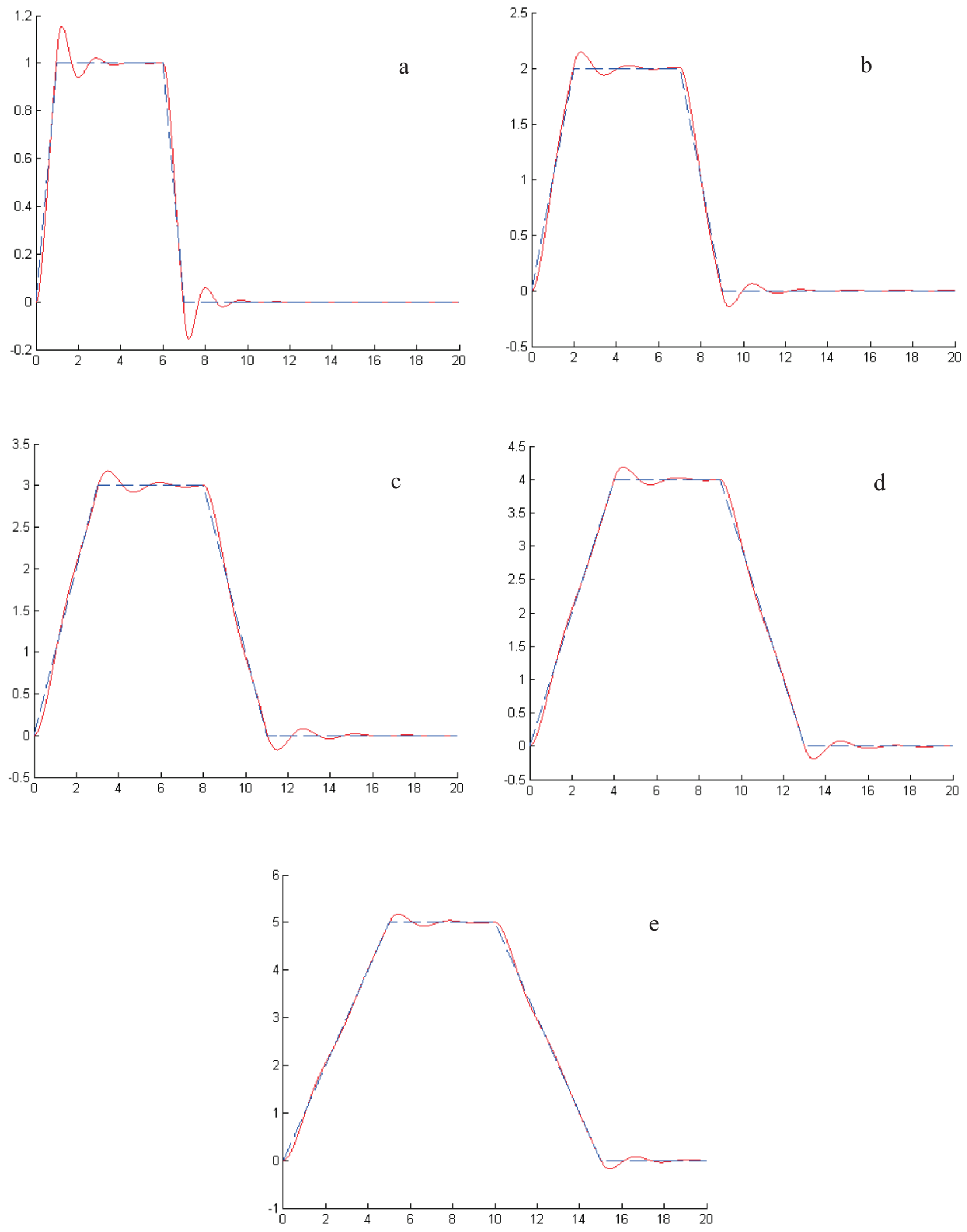

Figure 7. Time response of the $E V$ under the action of the adaptive $P I D$ controller for ramp with an amplitude of a) $\left.\left.V e l_{R e f}=1 \mathrm{~km} / \mathrm{h} \mathrm{b}\right) V e l_{\text {Ref }}=2 \mathrm{~km} / \mathrm{h} \mathrm{c)} V e l_{\text {Ref }}=3 \mathrm{~km} / \mathrm{h} \mathrm{d}\right) V e l_{\text {Ref }}=4 \mathrm{~km} / \mathrm{h} \mathrm{e)} V e l_{\text {Ref }}=5 \mathrm{~km} / \mathrm{h}$ 
Table 5 refers to the PID parameters obtained experimentally. For the proportional gain $K_{p}$ we verify that it increases when the reference velocity $\mathrm{Vel}_{\text {Ref }}$ increases. The derivative time $T_{d}$ will depend on the error between the reference velocity and the real velocity. The integral time will depend either the vehicle is accelerating or decelerating (in other words it will depend on the relation between the reference and the real velocity).

As previously analyzed with the classical PID we will now study the system dynamics under the action of the adaptive $P I D$ controller when applying the ramp signals at the reference (Figure 7).

Table 6 shows the time response characteristics of the adaptive $P I D$, namely the percent overshoot $P O$, the rise time $t_{r}$, the peak time $t_{p}$ and the settling time $t_{s}$.

Table 5

PID parameters experimentally obtained

\begin{tabular}{|c|c|c|c|c|}
\hline $\operatorname{Vel}_{\text {Ref }}(\mathrm{Km} / \mathrm{h})$ & $\operatorname{Vel}_{\text {Real }}(\mathrm{Km} / \mathrm{h})$ & $K$ & $T_{i}$ & $T_{d}$ \\
\hline \multirow{2}{*}{$V e l_{R e f} \leq 1$} & $\leq V e l_{R e f}$ & \multirow{2}{*}{50} & 1.5 & \multirow{2}{*}{$0.375 . \varepsilon_{v e l}$} \\
\hline & $>V e l_{R e f}$ & & 5 & \\
\hline \multirow{2}{*}{$1<V e l_{\text {Ref }} \leq 2$} & $\leq V e l_{R e f}$ & \multirow{2}{*}{150} & 1.2 & \multirow{2}{*}{$0.375 . \varepsilon_{v e l}$} \\
\hline & $>V e l_{R e f}$ & & 6 & \\
\hline \multirow{2}{*}{$2<V e l_{R e f} \leq 3$} & $\leq V e l_{R e f}$ & \multirow{2}{*}{200} & 1 & \multirow{2}{*}{$0.375 . \varepsilon_{\text {vel }}$} \\
\hline & $>V e l_{R e f}$ & & 7 & \\
\hline \multirow{2}{*}{$3<V e l_{\text {Ref }} \leq 4$} & $\leq V e l_{R e f}$ & \multirow{2}{*}{250} & 0.8 & \multirow{2}{*}{$0.375 . \varepsilon_{v e l}$} \\
\hline & $>V e l_{R e f}$ & & 8 & \\
\hline \multirow{2}{*}{$V e l_{\text {Ref }}>4$} & $\leq V e l_{R e f}$ & \multirow{2}{*}{300} & 0.6 & \multirow{2}{*}{$0.375 . \varepsilon_{v e l}$} \\
\hline & $>V e l_{R e f}$ & & 9 & \\
\hline
\end{tabular}

Table 6

Time response parameters of the system under the action of the adaptive $P I D$ controller

\begin{tabular}{|l|l|l|l|l|}
\hline $\boldsymbol{V}_{\text {refmax }}(\mathbf{K m} / \mathbf{h})$ & $\boldsymbol{P O}(\boldsymbol{\%})$ & $\boldsymbol{t}_{\boldsymbol{r}}$ & $\boldsymbol{t}_{\boldsymbol{p}}$ & $\boldsymbol{t}_{\boldsymbol{s}}$ \\
\hline $\boldsymbol{1}$ & 15.43 & 1.00 & 1.23 & 4.80 \\
\hline $\mathbf{2}$ & 7.19 & 2.00 & 2.33 & 6.20 \\
\hline $\mathbf{3}$ & 5.78 & 3.05 & 3.50 & 7.00 \\
\hline $\mathbf{4}$ & 4.63 & 4.00 & 4.43 & 8.50 \\
\hline $\mathbf{5}$ & 3.47 & 5.00 & 5.45 & 9.70 \\
\hline
\end{tabular}

The adaptive $P I D$ controller presents better results than the classical PID controller revealing a smaller overshoot and a better time response to the perturbation.

\section{Conclusion}

A real-time adaptive PID digital controller has been developed that controls the speed of a DC motor in a closed loop manner. A Siemens PLC is used to implement the control.

In this paper were obtained satisfactory results in the velocity control of the EV proving that the implementation of the adaptive PID is more efficient than the classical PID and leads to a superior response.

\section{References}

[1] Donald L. Anglin, Electric Vehicle. AccessScience McGraw-Hill, 2008.

[2] P. Khatun, C.M. Bingham, N. Schofield, and P.H. Mellor. Application of Fuzzy Control Algorithms for Electric Vehicle Antilock Braking/Traction Control Systems. IEEE Transactions on Vehicular Technology, Vol. 52, Issue: 5, pp.1356-1364, 2003.

[3] R. Saeks, C.J. Cox, J. Neidhoefer, P.R. Mays and J.J. Murray, Adaptive Control of a Hybrid Electric Vehicle, IEEE Transactions on Intelligent Transportation Systems, Vol.3, Issue: 4, pp.213-234, 2002.

[4] Rui Paulo Rocha, State of the Art of Mobile Robot in Portugal, Assistant of Department of Electrical Engineering and the FCTUC Researchers ISR Coimbra, 2001.

[5] S. Butdee, A. Suebsomran, F. Vignat, P.K.D.V. Yarlagadda, Control and path rediction of an Automate Guided Vehicle, Journal of Achievements in Materials and Manufacturing Engineering, Volume 31, Issue: 2, 2008.

[6] T. C. Kuo, Member, IAENG, Y. J. Huang, Member, IAENG, C. Y. Chen, and C. H. Chang, Adaptive Sliding Mode Control with PID Tuning for Uncertain Systems, Engineering Letters, 2006.

[7] Jin Cao, Xiao Liao and Ernest Hall, Reactive Navigation for Autonomous Guided Vehicle Using the Neuro-fuzzy Techniques, Center for Robotics Research, ML 72 University of Cincinnati, 1999.

[8] Micael S. Couceiro, Rui Mendes, N. M. Fonseca Ferreira, J. A. Tenreiro Machado "Control Optimization of a Robotic Bird”, EWOMS '09, Lisboa, Portugal, 2009a

[9] Micael S. Couceiro, N. M. Fonseca Ferreira, J. A. Tenreiro Machado "Application of Fractional Algorithms in the Control of a Robotic Bird", in the Journal of Communications in Nonlinear Science and Numerical Simulation, Special Issue, Elsevier 2009b

[10] K.J. Aström, T. Hägglund, PID Controllers - Theory, Design and Tunning, Instrument Society of América, 67 Alexandre Drive, POBox 12277, Research Triangle Park, North Carolina 27709, USA, 1995. 